\title{
Martirén, Juan Luís. La transformación farmer: colonización agrícola y crecimiento económico en la provincia de Santa Fe durante la segunda mitad del siglo XIX. Buenos Aires: Prometeo libros, 2016, 266 p.
}

\author{
Jonas Moreira Vargas* \\ * Departamento de História e do Pós-graduação em História da Universidade Federal de Pelotas, Brasil | \\ jonasmovargas@gmail.com
}

Nas últimas décadas do século XIX, a Argentina tornou-se uma das maiores exportadoras de trigo das Américas. É bem verdade que nesta época o porto de Buenos Aires também apresentou altos índices de remessas de carnes congeladas e refrigeradas para o exterior, mas a presença de cereais entre os produtos mais negociados tratava-se de uma importante alteração na matriz agroexportadora do país, visto que até então os produtos de origem pecuária, como os couros, o tasajo e a lã não deixavam muito espaço para os gêneros agrícolas nas exportações. Para algumas regiões argentinas que se especializaram na cultura do trigo, atendendo a forte demanda por alimentos que as grandes cidades do mundo atlântico vinham apresentando, aquele fenômeno socioeconômico foi profundamente transformador.

A obra de Juan Luís Martirén está dividida em seis capítulos e nos convida, de forma instigante, a conhecer melhor os fatores socioeconômicos e institucionais internos que possibilitaram tal mudança ao mesmo tempo em que evidencia os impactos causados pela economia farmer em uma determinada região da Argentina. Refiro-me à província pampeana de Santa Fé e os seus territórios que foram alvo de uma importante política de colonização entre as décadas de 1850 e 1890 . Após a fase de maturação das colônias, Santa Fé tornou-se produtora de mais da metade do trigo argentino, viu as suas estruturas socioeconômicas internas se alterarem profundamente e serviu de exemplo para que suas vizinhas pampeanas investissem no mesmo processo colonizador.

Mas que transformação foi essa? Nas palavras de Martirén, o processo de colonização agrícola ocorrido em Santa Fé na segunda metade do século XIX foi um dos exemplos mais interessantes de reconversão produtiva no mundo capitalista moderno. Se no início a produção agrícola era mais diversificada, restrita ao 
abastecimento nacional e com sérios limites para desenvolver-se, nos anos 1880 o progresso tecnológico havia atingido altos níveis, ampliando a produtividade e as áreas cultiváveis especializadas no plantio do trigo. Esta década também marcou a entrada do trigo argentino no mercado internacional e uma expansão agrária para as províncias vizinhas, fomentada pela acelerada entrada de imigrantes. Pode-se dizer que a transformação farmer promoveu a expansão das fronteiras agrícolas, a ampliação da malha ferroviária, o desenvolvimento tecnológico agrário, o fluxo de capitais para o campo e a introdução de um mercado de terras mais formal.

Fruto de sua Tese de doutorado em História defendida em 2013 na Universidad Nacional del Centro de la Provincia de Buenos Aires, o livro apresenta-se ao leitor como um genuíno representante da historiografia que há décadas vem renovando a imagem tradicional que se tinha a respeito do mundo agrário argentino desde os tempos coloniais. Na realidade, Martirén faz parte de uma jovem geração que tem como mestres nomes como Jose Carlos Chiaramonte, Hilda Sabato, Juan Carlos Garavaglia, Roberto Schmidt, Raul Fradkin, Jorge Gelman, Julio Djenderedjian, entre outros, e não nos surpreende que muitas das perguntas que nortearam as pesquisas destes historiadores continuam atuais e estão presentes na obra do autor. Estou me referindo às preocupações macroeconômicas que auxiliam na compreensão de processos globais como a formação de mercados regionais e nacionais para gêneros básicos; a inserção da economia platina no comércio atlântico; o surgimento dos mercados de trabalho, de capitais e de terras; as inovações tecnológicas e as mudanças de produtividade na economia agrária; a igualdade e a desigualdade de oportunidades e condições materiais nos processos econômicos; o surgimento de novos grupos sociais e as hierarquias provocadas pelo avanço do capitalismo; a expansão agrária nas fronteiras agrícolas e os seus fatores determinantes.

No entanto, Martirén avança em diversos aspectos e tem a sua própria agenda de investigação, pois a sua pesquisa bebe muito da história social, não apenas nos aspectos seriais e quantitativos caros aos Annales, mas também nas análises qualitativas, lembrando, em alguns momentos, as importantes contribuições trazidas pela Micro-história italiana de corte mais socioeconômico, como a praticada por Giovanni Levi e Edoardo Grendi. Tal faceta fica mais evidente na análise das estratégias dos empresários e das hierarquizações sociais nas colônias. Outra questão que deve ser destacada diz respeito à variedade, quantidade e riqueza das fontes documentais pesquisadas e a forma organizada e criativa com que o autor as analisa e interpreta. São fontes políticas, fiscais, econômicas, notariais, arquivos privados de empresários, proprietários e comerciantes, jornais da época, estatísticas, relatórios, correspondência oficial e privada, entre outros. Diversos critérios metodológicos e dados disponibilizados, assim como gráficos, tabelas e mapas, estão presentes no livro. Em suma, o avanço da investigação empírica permitiu a Martirén obter uma visão mais complexa e adequada da transformação farmer ocorrida no mundo agrário pampeano trazendo uma fundamental contribuição à historiografia argentina sobre o século XIX. Com tantos méritos, não nos causa surpresa que a sua pesquisa tenha recebido, com todo o merecimento, o primeiro lugar no $V$ Concurso de Tesis de Doctorado de la Asociación Argentina de Historia Económica (2014).

Os dois primeiros capítulos são mais gerais e tratam da economia provincial no século XIX. O ano de 1856 marca a fundação da primeira colônia: Esperanza. Os anos iniciais foram de muitas dificuldades, pois apesar da existência de uma considerável oferta de terras, os mecanismos para viabilizar a expansão ainda eram precários. Conforme Martirén foi a Guerra do Paraguai (1864-1870) a responsável por “desafogar” essa etapa inicial da colonização. Como os exércitos acampados ficavam muito próximos das fronteiras santafesinas, os colonos foram favorecidos com o aumento da demanda por gêneros e a alta dos preços. A reconversão de capitais na região desenvolveu-se muito nos anos 1870 e o número de colônias se proliferou tanto ao sul quanto ao oeste do núcleo inicial. Os dados estatísticos decorrentes de tal processo são bastante eloquentes: se nos anos 1850 existiam somente 3 colônias reunindo poucos hectares de terras, nos anos 1890, 
Santa Fé já possuía mais de 400 colônias que juntas superavam um milhão de hectares. O impacto demográfico foi marcante e a população colonial saltou de $10 \%$ nos anos 1860 para $40 \%$ do total da província na década de 1880 .

Tal processo de colonização provocou uma série de transformações institucionais e socioeconômicas. Investimentos estatais envolvendo os sistemas notariais, de transporte e finanças foram fundamentais, trazendo uma moeda forte e créditos disponíveis para a colonização, a ampliação das estradas de ferro, um povoamento mais planejado e seguro nas fronteiras com os povos indígenas e compra e venda de terras com maiores garantias. A oferta abundante de terra e a entrada de imigrantes combinou-se com um grande fluxo de capital em tecnologia. O aumento da quantidade de "arados”, “máquinas de segar”, "rastras” e "rastrillos”, "trilladoras a vapor" entre 1872 e 1895 foi fantástico, resultando num aumento progressivo da produtividade. A colonização agrícola transformou a estrutura fundiária, financeira, produtiva e demográfica da província.

O capítulo terceiro trata do impacto que a colonização causou no mercado de terras da região. Conforme Martirén, no novo contexto já não bastava mais recorrer à palavra ou às redes clientelares para garantir a propriedade da terra, sendo cada vez mais necessário a formalização contratual das transações. Para compreender o funcionamento desse mercado o autor analisou 3.625 escrituras públicas de compra e venda de imóveis rurais, demonstrando que o mercado de terras de pastoreio não acompanhou a alta de preços no mercado de terras nas colônias e que, nos anos 1880 e 1890, a discrepância entre ambos os mercados ficou mais evidente. É de notável importância considerar que vários fatores influíam nesse mercado, como a proximidade com alguma malha ferroviária, com algum porto ou centro urbano, a antiguidade da ocupação, o preço do trigo no momento da transação, a conjuntura política ou de guerra, o dinamismo econômico local, a produtividade da terra, a presença indígena em suas fronteiras, a competição da área com o pastoreio, entre outros. A constatação de Martirén é de que a transformação farmer provocou um ciclo especulativo sobre o mercado de terras a partir dos anos 1880, atraindo muitos investidores e dinamizando ainda mais esse mercado. Ouso afirmar que não é possível estudar os mercados de terra na América Latina do oitocentos sem ler as contribuições de Martirén para o tema.

No capítulo quarto o autor segue uma tendência cada vez mais comum na história econômica: a análise da trajetória de empresários, investidores e negociantes envolvidos em tais processos econômicos. Trata-se de uma fundamental chave analítica que favorece a compreensão do funcionamento dos sistemas econômicos agrários e pré-industriais. Os casos de Mauricio Franck, Juan Godeken e Guillermo Lehmann ajudam o autor a perceber melhor as estratégias políticas e econômicas dos empresários da colonização para obter ganhos em um investimento que, de início, era cheio de dificuldades estruturais. Os cálculos de rentabilidade evidenciam que as taxas de retornos não eram tão atrativas incialmente, pois havia uma certa dificuldade em cobrar as dívidas estabelecidas com os colonos recém-chegados. Neste sentido, o investimento era atrativo apenas para aqueles que conseguiam cobrar o maior número de dívidas ou suportar por mais tempo a concessão de créditos. O autor percebe que muitos destes empresários de sucesso estavam inseridos em redes de relações que lhes favoreciam com informações privilegiadas junto ao Ministério do Interior e Comissões de imigração. Conforme Martirén, os grandes empresários operavam com uma vantagem competitiva fundamental: a tolerância dos ciclos de amadurecimento de uma colônia. Eles estavam inseridos, por um lado, em redes de brokers que facilitavam os contatos com colonos e proprietários e, por outro, a agentes lobistas que convenciam investidores em estradas de ferro ou obras públicas benéficas aos seus investimentos.

Engana-se quem pensa que por se tratar de um espaço agrário distinto das tradicionais áreas de pastoreio não havia desigualdade na distribuição de riqueza. No capítulo 5, Martirén estuda, a partir dos registros de contribuição direta entre os anos 1860 e 1880, os padrões de acumulação nas colônias. Em Esperanza, nos anos 1870, o colono mais rico possuía uma fortuna 19 vezes maior que o mais pobre. Na mesma localidade, 
os $20 \%$ mais ricos detinham $50 \%$ do patrimônio. Mas apesar destes dados aquela economia farmer gerou uma sociedade mais complexa. Martirén localiza nas fontes uma gama de sujeitos, profissões e grupos sociais distintos, evidenciando uma estratificação complexa que o autor relaciona com a mobilidade social e o acúmulo de fortunas. Os indicadores trazidos revelam um predomínio de agricultores - como não poderia ser diferente - mas também destacam os donos de moinho, dos comerciantes e dos rentistas no topo da pirâmide. A análise das faixas etárias revela a importância do ciclo vital na mobilidade social, pois muitos acumulavam bens e tornavam-se proprietários plenos na casa dos 30 ou 40 anos, refletindo um processo de acumulação de capital e trabalho coletivo que esboçavam uma notável estratégia familiar de reprodução.

O último capítulo é um dos mais instigantes e fundamentais. A partir de uma gama variada de fontes documentais, Martirén analisa as bases concretas desse novo esquema que se buscava implantar naquela época, dando ênfase ao estudo dos custos de produção e da produtividade total fatorial. Se escritos mais tradicionais centraram o sucesso do crescimento agrário colonial no fator terra negligenciando a importância do fator técnico, o autor trata de reabilitar a importância deste último. Para Martirén, a capitalização da produção trigueira santafesina e não a terra em si foi o principal componente do processo de expansão. Neste sentido, a oportunidade para produzir nos anos 1880 era ótima, pois o acúmulo de capital e know-how da década anterior oferecia boas condições para a incorporação produtiva das novas terras da fronteira, que tinham uma malha ferroviária ainda mais ampla e uma notável demanda do mercado mundial de trigos. Em suma, a economia farmer apresentava grandes níveis de crescimento num processo com retroalimentação própria.

Se eu tivesse que fazer uma ressalva diria que analisar a trajetória de empresários fracassados (e não somente daqueles que tiveram sucesso) também ajuda na compreensão das incertezas e das dinâmicas da mobilidade social e dos investimentos coloniais naquele contexto. Algumas vezes as falências e "derrotas” são tão eloquentes quanto as "vitórias" e talvez algum dia Martirén possa nos brindar com um artigo a respeito das tentativas fracassadas ocorridas naquela época. No entanto, isto não afeta em nada o brilhantismo da pesquisa do autor. O livro de Juan Luis Martirén é um belo manual de como formular novas perguntas e buscar respostas para estas questões fundamentais a respeito da história econômica nas Américas. Alguns capítulos, tendo em vista o rigor teórico e metodológico do autor, parecem-se com uma receita de um saboroso bolo. Confeiteiros iniciantes na pesquisa histórica e nas reflexões caras a história econômica tem nas páginas de La transformación farmer um repertório de ingredientes que podem servir como base para seus estudos, muito embora, como se sabe, o sabor do bolo pode não ser o mesmo. Isto porque o talento de Martirén na análise dos documentos é algo que só se atinge com alguma erudição e maturidade - algo raro em historiadores jovens como ele. 